\title{
O seminário, livro 13: o objeto da psicanálise, de Jacques Lacan
}

\section{Glaucia Nagem de Souza e Luciana de Freitas Guarreschi}

\section{Traduzir: o quarto impossível (Apresentação do livro, por Lu- ciana de Freitas Guarreschi)}

Para além do incontornável e injusto "traduttore, traditore" - tradutor, traidor - , arriscarei algumas palavras sobre traduzir. Estarei acompanhada por Italo Calvino, em Mundo escrito e mundo não escrito (2015); Boris Schnaiderman, em Tradução, ato desmedido (2011); alguma experiência na área; e a assistência e revisão técnica de $O$ seminário, livro 13: o objeto da psicanálise, de Lacan (1965-1966/2018). Embora Italo e Boris refiram-se à tradução literária, reencontrei neles algum alento neste momento de publicação da tradução do Seminário 13, e quase tudo do que segue foi deles retirado, bricolado, por mim. Comecemos pelo começo: a escolha do tradutor.

Ao contrário do comumente "recomendado" para a tradução da língua francesa em portuguesa, escolhemos um tradutor francês, e não brasileiro. A questão é que os analistas não aceitam de imediato o que é comumente recomendado, preferindo buscar suas próprias medidas. Assim, a escolha recaiu sobre dois fatores; primeiramente, as dúvidas. Um tradutor que não tem dúvidas não pode ser um bom tradutor: o primeiro julgamento sobre a qualidade de um tradutor decorre do tipo de questão que ele faz, ensina Calvino. Eu já conhecia Luc Matheron há bastante tempo para saber de seu apreço por perguntar. Mas ele foi além: qual não foi minha satisfação ao chegar para uma de nossas revisões e vê-lo sentado com duas Bandas de Moebius coladas, coloridas e cortadas, dizendo-me algo assim: "Não acreditei no que li, tive que montá-las para ver se estava correto. Você sabia disso? Sabia que elas se desmontam em duas?" Ao que só pude rir e fotografar a cena.

O segundo fator estabelecia como necessário estar em relação direta com o tradutor, não apenas virtualmente, mas encontrando-o ao vivo para discutir as escolhas de tradução, principalmente no início, para estabelecer o "padrão" da tradução. Busco trazer essas discussões aqui, pois me ensinaram muito.

Ensinaram que cada tradutor esmera-se, torna-se "menos ruim" pela autocrítica, e nesse caminho a lição das mancadas é tão importante quanto a dos êxitos (Freud sempre avisou, né?). No caminho, apreende-se que o arrojo e a ousadia são 
tão necessários na tradução como a fidelidade ao original, ou ainda a fidelidade só se obtém com certa dose de liberdade no trato com o texto.

Ensinaram também que é preciso cuidado com as faixas semânticas. Sábato (Ernesto Sábato, escritor argentino), em uma discussão com Borges, diz: "a rigor, qualquer tradução é falsa, não existem equivalentes exatos”, ao que Borges replica: "isso é culpa dos dicionários, que nos fizeram acreditar na existência dos equivalentes, o que não é verdade” (Schnaiderman, 2011, p. 26). Freud avisou, Lacan confirmou.

Mais além, há o perigo da lógica estrita e rigorosa: Abrasileirar, então? Manter afastamento? O que fazemos com o faire avancer? Que, nas traduções lacanianas (dei-me conta, neste trabalho, de que há pelo menos três tipos de tradução: a literária, a técnica e as lacanianas), sempre se transforma em "fazer avançar", ou seja, uma tradução dita "literal". Mas não poderia ser desenvolvimento? Poderia? Desenvolvimento soa progressão quantitativa no novo mundo. C'est pas la même chose que "faire avancer" no velho mundo.

Sigo. Precisão semântica e precisão do tom: qual o equilíbrio im-possível entre os dois? Preferindo-se o primeiro, o texto tende a ficar duro e explicativo demais, falseia-se o original. Jogando-se mais com segundo - a precisão do tom - , ahhh, o tom em Lacan... o tom de Lacan! Quoi faire? Traduzir é o mais absoluto sistema de leitura, é necessário ler o texto nas implicações de cada palavra. Para o tradutor, os problemas a resolver nunca diminuem. Nos textos em que a comunicação é mais coloquial, se o tradutor conseguir colher o tom justo desde o início, ele pode seguir nesse embalo com uma desenvoltura que parece - deve parecer fácil. Mas traduzir nunca é fácil. Há casos em que as dificuldades são resolvidas espontaneamente, quase inconscientemente, pondo-se em sintonia com o tom do autor; no entanto, para textos estilisticamente mais complexos, com diferentes níveis de linguagem que se corrigem reciprocamente, as dificuldades devem ser resolvidas frase a frase, seguindo o jogo do contraponto, as intenções conscientes ou as pulsões inconscientes do autor.

Um pouco mais: linguagem comum ou jargão profissional? Aqui, quem responde, em cartas com seu tradutor alemão, é Guimarães Lacan Rosa. Ele diz:

Mas Corpo de baile tem que ter suas passagens obscuras. Isto é indispensável!! A excessiva iluminação geral, só no nível do raso, da vulgaridade. Todos os meus livros são simples tentativas de rodear e devassar um pouquinho o mistério cósmico, esta coisa movente, impossível, perturbante, rebelde a qualquer lógica, que é chamada "realidade" que é a gente mesmo, o mundo, a vida. Antes o obscuro que o óbvio, que o frouxo. Toda lógica contém inevitável dose de mistificação. Toda mistificação contém boa dose de inevitável verdade. Precisamos também do obscuro. É preciso então 
aventura e mistificação, sempre é melhor explicar menos e deixar a frase mais intensa, concentrada, forte. (Schnaiderman, 2011, p. 53)

O tradutor é jogado no redemoinho: a tradução perfeita não existe, e o erro nos espreita em cada esquina. Por aqui, nada de Lacan elucidado. Um viva à estranheza gramatical e às palavras enganosas!

Mas... não falaremos de nossa tradução: o direito de julgá-la pertence inteiramente ao público. Mas, ainda assim, valem umas palavrinhas sobre as críticas, mencionando o caso mais frequente: o lapso. Com certeza, o lapso deve ser criticado. Mas isso não basta para julgar uma tradução. Às vezes, o lapso oculta-se na página do tradutor mais experiente e respeitável, e não no teste do novato. Assim, a abordagem crítica de uma tradução deve ser feita com base em um método, sondando amostras amplas que possam servir como decisivas.

Em 2002, uma pesquisa na Espanha sobre tradutores mostrou que essa é a profissão mais mal paga do mundo, a ser levado em conta o trabalho exigido (alguns inclusive a fazem quase de graça, ou de graça mesmo!). O tradutor é um profissional altamente qualificado, tem de manejar à perfeição, no mínimo, dois idiomas, acumular os mais diversos conhecimentos. Tanto trabalho em troca do quê? Às vezes, tem-se a impressão de praticar uma atividade clandestina: o reconhecimento intelectual e social do trabalho, embora crescente, ainda é modesto. A grande incógnita é por que gente tão preparada escolhe dedicar-se à tradução, e não a atividades mais bem remuneradas. Não há resposta, há pistas: o amor à língua é coisa bem diversa e nasce, vibra de uma neurose mais aguda e inteiramente outra.

Por fim, há quem veja aí um ganha-pão honesto e muito árduo, uma tarefa como outra qualquer, mas a passagem de um texto para outra língua requer a todo instante uma espécie de milagre, inclusive em análise. A tradução é ato desmedido, miséria e esplendor, céu e inferno. Impossível, em princípio, a tradução tem de ser feita. Aí está a nossa.

\section{A história de uma tradução e suas consequências para a clínica (Resenha, por Glaucia Nagem de Souza)}

Vale contar um pouco da história do trabalho dessa tradução. Em 2015, quando assumi, junto com as colegas Luciana Guarreschi, Samantha Abuleac e Gisela Armando, o biênio 2015-2016 de gestão do Fórum São Paulo, decidimos trabalhar como um cartel. E fiquei muito feliz, pois o primeiro lançamento da tradução do Seminário 13 foi feito em uma jornada de cartéis. Trabalhar assim proporcionou à nossa gestão da época uma oportunidade de que nos responsabilizássemos tanto pelo trabalho exigido por nossas funções quanto pelo que cada uma ia fazendo. Por isso, mesmo que eu e Luciana tenhamos cuidado da revisão dessa tradução, uma vez que nos cabia pelas funções que cumpríamos na época, Gisela, como 
tesoureira, e Samantha Abuleac, como coordenadora das Formações Clínicas, estiveram presentes apoiando e trabalhando juntas.

A ideia aconteceu quando Luciana, que era secretária da gestão na época, estava escrevendo um caso que posteriormente apresentou, para o qual se baseava no Seminário 13. Nesse ano, eu trabalhava o mesmo texto em meu próprio seminário. Constatamos que não havia nenhuma tradução sua em português. Abraçamos essa proposta, apoiadas não apenas por Gisela e Samantha, como também pelos colegas Luis Guilherme Mola e Ana Paula Gianese, da então comissão de publicação, que apoiaram o seguimento do projeto.

Ter acesso ao texto de Lacan é algo que faz toda a diferença na formação de um psicanalista que se disponha a seguir suas indicações teórico-clínicas. Sabemos que há certo descaso dos detentores dos direitos de publicação dos seminários para finalizar aqueles que ainda não estão estabelecidos. Esse descaso tem um peso político na formação dos analistas interessados na teoria de Lacan. Não apenas esse seminário, mas alguns outros e ainda escritos importantes encontram-se sem estabelecimento oficial e, portanto, sem tradução. Isso mantém alguns textos e pontos cruciais da teoria herméticos, só sendo acessados por alguns que conhecem a língua francesa.

Assim, traduzir para o português um seminário é também um ato político. Uma abertura para que sigamos estudando e abrindo questões importantes sobre os desenvolvimentos teóricos de Lacan.

Apesar de a primeira aula desse seminário - "Ciência e verdade” — já estar estabelecida nos Outros escritos, resolvemos traduzi-la junto das outras para que ela compareça na leitura com o mesmo peso e estilo. Além disso, não retiramos das lições fechadas as intervenções dos psicanalistas que frequentavam os seminários de Lacan, mesmo que logo em seguida o próprio Lacan discorde do que foi dito, ou que saibamos que posteriormente alguns desses analistas romperiam com ele. Mesmo sabendo que o que está exposto seria abandonado, entendemos que era importante que se tivesse acesso ao texto na íntegra. A partir daí, cada leitor poderia fazer suas pesquisas do que está exposto e trabalhar as questões abertas pelo movimento do seminário.

\section{Algumas dicas importantes}

O título desse seminário não traz nenhum jogo de palavras ou homofonias. No entanto, propõe que Lacan falará do Objeto da Psicanálise quando o conteúdo do seminário traz a todo tempo um questionamento sobre a posição do sujeito. Onde está o sujeito? Qual sua relação com o objeto?

Lacan abre o seminário recomendando a leitura do texto de Foucault As palavras e as coisas (1966/2007), no qual esse autor faz uma análise minuciosa do quadro As meninas, de Velásquez. Ele faz uma leitura minuciosa desse texto e o 
vemos reafirmar, contrariamente ao filósofo, que não há representação pura, mas representante da representação.

O que Lacan se esforçará a partir daí até o final desse seminário será demonstrar, principalmente pela topologia de superfície, os lugares do sujeito e do objeto. Nesse percurso, temos as variantes dos cortes sobre essas superfícies, que Lacan tratará como as possíveis intervenções do analista. Pela topologia de superfície e seu manejo, podemos acompanhar, a partir dos cortes, mudanças nas estruturas, e não mudanças de estruturas. Sabemos como isso é importante para tratarmos a clínica.

Chapuis, em seu livro Guía topológica para L'étourdit (2012), adverte-nos de que, na lição 3 desse seminário (e acrescentamos também a lição 6), encontramos praticamente todo o desenvolvimento que Lacan faz na segunda parte de "O aturdito" (Lacan, 1973/2003). Se pensamos que "O aturdito" é um texto que anuncia uma virada no ensino de Lacan na passagem do modal para o nodal, isso de alguma forma já estava sendo forjado nesse seminário que traduzimos. Convido que paremos nessa lição 3 como certo aperitivo para a leitura desse seminário.

Qual o objeto da psicanálise? Ora, podemos responder rapidamente: o sujeito. Mas que sujeito? Lacan retoma, na página 57, o significante como sendo o "que representa o sujeito, e para outro significante"1 (Lacan, 1965-1966/2018, p. 26). Treze anos se passaram, e o peso dos significantes permanece. Que o analista possa escutar o sujeito como efeito dos significantes é o que alavanca todo o retorno a Freud feito por Lacan.

O sujeito localizado entre os significantes é o que a prática da fala em análise nos proporciona, sendo isso a marca da divisão estrutural de todo e qualquer sujeito falante. O choque provocado, como nos ensina Freud no "Projeto" (1895/1966), do sujeito com seu semelhante. Nessa lição, temos que "o objeto(a) esteja ligado, enquanto queda, à emergência, à estruturação do sujeito enquanto divisão (...)”2 (Lacan, 1965-1966/2018, p. 30).

Aos poucos, Lacan vai apresentando a série conceitual que vinha construindo nos anos anteriores. Mas como dizer disso sem cair no comportamento ou nos fenômenos? Ele responde na sequência: "Nenhum vazio, nenhuma queda do objeto(a), nenhuma angústia primária é suscetível de mostrá-la [a divisão do sujeito], e vou tentar fazer com que vocês o percebam por meio de considerações topológicas"3 (Lacan, 1965-1966/2018, p. 31).

1 No original: "qu'il représente le sujet, et pour un autre signifiant".

2 No original: "I'objet(a) soit lié en tant que chute, à l'émergence, à la structuration, du sujet comme division (...)".

3 No original: "Aucun vide, aucune chute de l'objet(a), aucune angoisse primordiale n'est susceptible d'en rendre compte, et je vais essayer de vous le faire sentir par des considérations topologiques". 
A topologia de superfície é retomada, pois, por suas características, podemos pensar em mudança na estrutura, e não da estrutura. Tanto é que um conceito princeps introduzido é o do homeomorfismo, definido como "(...) uma homologia topológica: duas figuras, quaisquer sejam, desde que providas de uma borda, podem ser, pela deformação dessa borda, demonstradas como homeomorfas" (Lacan, 1965-1966/2018, p. 32). Ora, as mudanças promovidas pelos cortes das superfícies não geram superfícies novas, mas modificam a superfície anterior, mantendo sua estrutura. A nova superfície mantém-se homeomorfa à anterior.

Assim, com a topologia de superfície, Lacan encontra um modo matemático de dizer o que desde o início de seu ensino está em questão: os Cortes e as Modificações por eles promovidas. A topologia de superfície é aquela em que não se diferencia uma rosca de uma caneca, pois ela não se dá no espaço de três dimensões.

Em matemática, diz-se que:

Topologia é o ramo da geometria que lida com as propriedades de superfícies e formas em geral, mas não engloba medidas de comprimento ou ângulos. Destacam-se as qualidades que não mudam quando formatos são transformados em outros formatos. Podemos empurrar e puxar o formato em qualquer direção e por isso a topologia é algumas vezes descrita como a "geometria da folha de borracha". Topólogos são pessoas que não conseguem perceber a diferença entre uma rosca e uma xícara de café! Uma rosca é uma superfície dotada de um só buraco. Uma xícara de café é a mesma coisa, mas o buraco toma a forma de uma alça. (Crilli, 2017, p. 94)

Assim, algumas questões apresentam-se: Como dizer de uma situação clínica sem cair no senso comum e nos afetos? Como ler os índices da estrutura? São questões por meio das quais podermos ver como a topologia entra na formalização da clínica. Acrescento ainda a abordagem de Pablo Amster em seu livro Notas matemáticas para ler Lacan. Ele nos diz que:

Em sua tentativa de desimaginarizar, Lacan se interessou por diversas questões que concernem à topologia, começando pelos grafos, passando pelas superfícies e chegando finalmente aos nós. Todos estes termos participam, de uma maneira ou de outra, da topologia. (Amster \& Torres, 2015, p. 29)

4 No original: "(...) une homologie topologique: deux figures, quelles qu'elles soient, en tant que pourvues d'un bord, peuvent être, par déformation de ce bord, démontrées homéomorphiques". 


\section{Voltando ao Seminário 13, ou: lá vem agora um pouco de topologia}

Assim, Lacan aborda, nessa lição 3, uma série de cortes que, como disse antes, serão retomados na segunda parte de "O aturdito". Mas, nesse seminário, de modo muito mais detalhado, ele começa pela Banda de Moebius e mostra que:

A banda de Möbius tem muitas propriedades. Uma é maior, capital, (...), que é uma simples e pura borda.

Não somente tem apenas uma borda à superfície da banda de Möbius, mas se a recorto pelo meio, não há mais banda de Möbius, pois é meu risco de corte, é a propriedade da divisão que institui a banda de Möbius. ${ }^{5}$ (Lacan, $1965-1966 / 2018$, p. 33)

Durante a tradução, surpreendemo-nos com o tradutor fazendo essa experiência, quando Luciana chegou para mais uma revisão. Lá estava ele com Bandas de Moebius inteiras e cortadas sobre sua mesa de trabalho, surpreso pela experiência. Assim, vale a pena, para cada um que se debruçar sobre esse seminário, fazer as experiências propostas. Deixo o cross-cap e a Garrafa para depois para me ater agora ao que em seguida será retomado em "O aturdito": ele apresenta o toro, que tinha sido trabalhado detidamente em seu seminário sobre a Identificação. Leiamos:

(...) mostrei o valor exemplar que o toro poderia ter para ligar, de forma estruturalmente dogmática, a função da demanda e do desejo propriamente dito (...).

O que se pode estruturar do sujeito é inteiramente ligado, estruturalmente à possibilidade de transformação, de passagem da estrutura do toro à da banda de Möbius (...). ${ }^{6}$ (Lacan, 1965-1966/2018, p. 37)

Sobre essa construção, Bousseyroux comenta:

Assim, acompanhamos o que ele apresentará de modo mais sintético alguns anos depois. Então, por que Lacan constrói esta topologia [das superfícies]? Para apresentar, na sua consistência topológica, o irrepresentável do objeto $a$ e, sobretudo, mostrar em uma abreviação surpreendente a modi-

\footnotetext{
5 No original: "La bande de Mœbius a de nombreuses propriétés. Il y en a une majeure, capitale, (...), que c'est un pur bord.

Non seulement il n'y a qu'un bord à cette surface de la bande de Mœbius mais si je la refends par le milieu, il n'y a plus de bande de Mœbius, car c'est mon trait de coupure, c'est la propriété de la division qui institue la bande de Mœbius".

6 No original: "(...) j'ai montré la valeur exemplaire que pouvait avoir le tore pour lier d'une façon structuralement dogmatisable, la fonction de la demande et celle du désir à proprement parler (...). Ce qui peut s'en structurer du sujet est tout entier lié structuralement à la possibilité de la transformation, du passage, de la structure du tore à celle de la bande de Mœbius (...)".
} 
ficação da estrutura a se resgatar de uma análise finalizada; lá onde estava o toro (bilátero e orientado) de minha neurose, eu devo advir ao moebiano (unilátero e não orientado) do desejo do analista, o corte que efetua o passe sendo a condição da dita modificação. Tal é a releitura do wo es war freudiano subjacente, parece-me, a apresentação lacaniana da modificação produzida pela operação analítica. (Bousseyroux, 2010, p. 8)

Em uma sequência topológica, temos quase um "passo a passo" do que se opera em uma análise.

Na experiência clínica: um sujeito, na medida em que se separa da confusão do toro do Outro, pode ficar dando voltas eternas no toro neurótico. O corte do analista visa a atingir, com os significantes, a fratura que o constitui como sujeito. A Cura é um procedimento que muda sem mudar. Uma metáfora simples para dizer disso é o processo de cura do queijo. O queijo entra fresco e pelo processo de cura sai curado. Ainda queijo, mas de outro modo.

Um primeiro corte de uma análise visa a separar a demanda e o desejo próprios do sujeito da demanda do Outro. Eu sou - frase que traz em si a ordem mortífera do Outro "Tu és". O que os primeiros cortes em uma análise visam é a que aquilo que do Outro determinou a alienação do sujeito possa se destacar e fazer a-parecer o que é do sujeito.

Posta essa separação, temos o esvaziamento para que o corte opere com aquilo do sujeito que pode extrair a banda de dupla volta de sua divisão. Sou isso e Sou aquilo. Divisão que põe a funcionar o que chamamos queda do objeto. E no percurso de uma análise a possibilidade de que algo se costure e o moebiano possa aparecer como a borda única do sujeito em questão.

Um exemplo no qual o tempo da divisão apresenta-se logo de saída:

E-mail: Gostaria de marcar um horário para fazer uma supervisão ou análise contigo.

Horário marcado.

Chega, senta-se e anuncia: Tive um sonho que te incluía.

Convite: Conte esse sonho no divã.

Conta o sonho.

Sessão termina. Pergunta: Por que o divã?

Resposta: Você escreve dizendo que queria supervisão ou análise. Chega com um sonho. Parece que escolheu a análise.

Resposta: Sério que escrevi isso?! Nem lembrava. Mas ok, é isso.

Análise começada. 
Não houve o tempo do "estou aqui porque o Outro fez isso ou aquilo". Chegou com a marca de corte entre os toros determinada. O corte entre desejo e demanda escancarado nas formações do inconsciente: no ato falho do e-mail e no sonho com a analista.

\section{Enfim, um pouco mais do Seminário 13}

Voltando ao seminário como um todo, há ainda uma revisão dos esquemas óticos a partir da introdução do cross-cap. Lacan mostra como na constituição dessa superfície topológica encontramos os elementos necessários para dizermos da constituição da fantasia. E ainda como que, no corte dessa superfície, temos a separação de uma Banda de Moebius e um disco. Essa separação é o que demonstra o funcionamento da fantasia que Lacan já vinha construindo conceitualmente desde muito antes desse seminário. Parece que esse seminário constrói o caminho necessário para que, no ano seguinte, Lacan escreva sobre A lógica do fantasma (1966-1967/2008). A construção dessa superfície dá-se de modo brilhante com a análise que Lacan fará a partir do texto de Foucault do quadro As meninas, de Velásquez.

Sabemos que a questão do olhar está posta muito precocemente na obra desse autor. Temos, já em 1932, toda a construção feita a partir da lógica do espelho no texto O estádio do espelho (Lacan, 1949/1998). No entanto, a abordagem do olhar a partir das superfícies traz um novo lugar para esse objeto. Talvez possamos já aqui observar o que Lacan fará explicitamente no Seminário 22 (1974-1975) com a retomada do Imaginário. O Olhar como objeto privilegiado na constituição do sujeito é um prenúncio da correção que, anos depois, Lacan fará do lugar do Imaginário para um sujeito.

Por fim, a arte entra, nesse seminário, de forma explícita. Temos um Lacan que recomenda a visita de uma exposição de Balthus no Museu de Artes Decorativas e compara um trabalho feito por esse artista com a posição dos olhares em $A s$ meninas. Além disso, há uma análise profunda do esquema de luzes do quadro As meninas e do quadro dentro do quadro das Fiandeiras, ambos de Velásquez. De quebra, temos ainda comentários sobre perspectiva, em que ele nos trará Van Eyck e Masaccio, Diego Rivera e Magritte.

É um seminário extremamente denso nos desenvolvimentos teóricos e ao mesmo tempo rico no uso da arte como fonte de articulações. Há ainda o clima intimista dos encontros fechados que tinham começado no seminário anterior. Neles, temos a presença das conversas atentas entre Lacan e alguns que frequentavam seus seminários. Tendo o próprio Foucault ido a um dos encontros, quando Lacan pergunta se ele teria deformado seu texto A palavra e as coisas, Foucault lhe responde que não, que ele o teria reformado. 
É com alegria que terminamos este trabalho. Trago esses pontos do seminário para que tenham vontade de lê-lo e para que possam descobrir outros pontos de interesse nessa leitura. É engraçado pensar que traduzimos esse texto e agora, ao o publicarmos, isso nos faz um pouco piratas. O que poderia ser interpretado como um bandido, se entendido pelo senso comum. Se pensarmos que com isso abrimos a teoria para mais pessoas, possibilitando o acesso a um texto tão importante, podemos nos dizer Fora-da-lei-do-Um. Talvez isso seja uma boa pirataria.

\section{Referências bibliográficas}

Amster, P., \& Torres, R. S. (Orgs.). (2015). Notas matemáticas para ler Lacan (Ronaldo Torres, Trad.) (1a ed.). São Paulo: Scriptorium.

Bousseyroux, M. (2010). Passe e fim pelo nó. Revista Digital Wunsch, 8. Recuperado de https://www.champlacanien.net/public/docu/4/wunsch8.pdf

Calvino, I. (2015). Mundo escrito e mundo não escrito. São Paulo: Companhia das Letras.

Chapuis, J. (2012). Guía topológica para L'étourdit: un abuso imaginario y su más allá. Barcelona: S\&P.

Crilli, T. (2017). 50 ideias de matemática que você precisa conhecer. (Helena Londres, Trad.) (1a ed.). São Paulo: Planeta.

Foucault, M. (2007). As palavras e as coisas: uma arqueologia das ciências humanas. (Salma Rannis Muchail, Trad.) (9a ed.). São Paulo: Martins Fontes. (Trabalho original publicado em 1966)

Freud, S. (1966). Projeto para uma psicologia científica. In S. Freud. Edição Standard Brasileira das Obras Psicológicas Completas de Sigmund Freud. Rio de Janeiro: Imago, 1996. V. I. (Trabalho original publicado em 1895)

Lacan, J. (1965-1966). Le seminaire, livre 13: l'objet de la psychanalyse. Inédito. Recuperado de www.starfela.free.fr.

Lacan, J. (1974-1975). O seminário, livro 22: RSI. Inédito.

Lacan, J. (1998). O estádio do espelho como formador da função do eu tal como nos é revelada na experiência psicanalítica. In J. Lacan. Escritos. Rio de Janeiro. Jorge Zahar. (Trabalho original publicado em 1949)

Lacan, J. (2003). O aturdito. In J. Lacan. Outros escritos (Vera Ribeiro, Trad.). Rio de Janeiro: Jorge Zahar. (Trabalho original publicado em 1973)

Lacan, J. (2008). O seminário 14: a lógica do fantasma. Edição não comercial exclusiva para os membros do Centro de Estudos Freudianos do Recife. (Trabalho original publicado em 1966-1967) 
Lacan, J. (2018). O seminário 13: o objeto da psicanálise. Edição não comercial destinada aos membros da Escola de Psicanálise dos Fóruns do Campo Lacaniano Brasil. (Trabalho original publicado em 1965-1966)

Schnaiderman, B. (2011). Tradução, ato desmedido. São Paulo: Perspectiva.

Recebido: $22 / 10 / 2018$

Aprovado: $22 / 10 / 2018$ 